Document downloaded from:

http://hdl.handle.net/10251/72988

This paper must be cited as:

Bernardos Bau, A.; Marina, T.; Zacek, P.; Pérez-Esteve, E.; Martínez-Máñez, R.; Lhotka, M.; Kourimská, L.... (2015). Antifungal effect of essential oil components against Aspergillus niger when loaded into silica mesoporous supports. Journal of the Science of Food and Agriculture. 95(14):2824-2831. doi:10.1002/jsfa.7022.

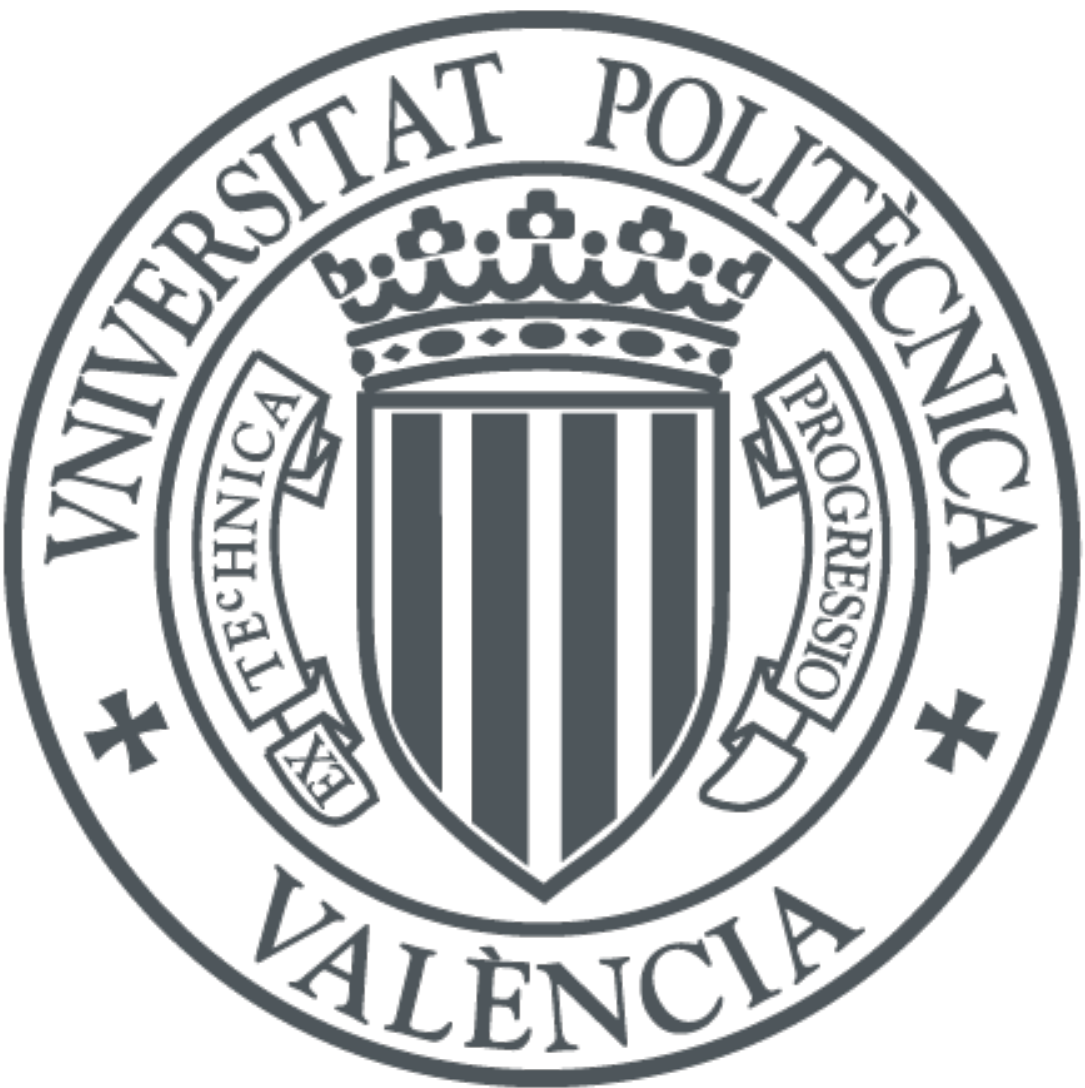

The final publication is available at

https://dx.doi.org/10.1002/jsfa.7022

Copyright Wiley

Additional Information 


\section{ANTIFUNGAL EFFECT OF ESSENTIAL OIL COMPONENTS AGAINST ASPERGILLUS NIGER WHEN LOADED INTO SILICA MESOPOROUS SUPPORTS}

Andrea Bernardos ${ }^{\mathrm{a}}$, Teresa Marina ${ }^{\mathrm{b}}$, Petr Žáček ${ }^{\mathrm{c}}$, Édgar Pérez-Esteve ${ }^{\mathrm{d}, \mathrm{e}}$, Ramón Martínez-Mañez ${ }^{\mathrm{d}, \mathrm{f}}$, Miloslav Lhotka ${ }^{\mathrm{g}}$, Lenka Kouřimskáb, Josef Pulkrábek ${ }^{\mathrm{a}}$, Pavel Klouček $^{\mathrm{b}, *}$

${ }^{a}$ Department of Crop Production, Faculty of Agrobiology, Food and Natural Resources, Czech University of Life Sciences Prague, Kamýcká 129, Prague 6-Suchdol, 165 21, Czech Republic.

${ }^{b}$ Department of Quality of Agricultural Products, Faculty of Agrobiology, Food and Natural Resources, Czech University of Life Sciences Prague, Kamýcká 129, Prague 6-Suchdol, 165 21, Czech Republic.

${ }^{c}$ Research Team of Infochemicals, Institute of Organic Chemistry and Biochemistry. Academy of Sciences of the Czech Republic. Flemingovo nám. 2, 16610 Prague 6. Czech Republic.

${ }^{d}$ Centro de Reconocimiento Molecular y Desarrollo Tecnológico (IDM), Unidad Mixta Universitat Politècnica de València - Universitat de València, Camino de Vera s/n, E-46022 Valencia, Spain.

${ }^{e}$ Grupo de Investigación e Innovación Alimentaria (CUINA), Universitat Politècnica de València, Camino de Vera s/n, E-46022 Valencia, Spain.

${ }^{f}$ CIBER de Bioingeniería, Biomateriales y Nanomedicina (CIBER-BBN). Monforte de Lemos 35, Pabellón 11,28029, Madrid, Spain.

${ }^{g}$ Department of Inorganic Technology, Faculty of Chemical Technology, Institute of Chemical Technology, Technická 5, 16628, Prague 6, Czech Republic

Correspondence to Pavel Klouček: E-mail: kloucek@af.czu.cz;

phone: +420224382536 ; fax: +420224382535 . 


\begin{abstract}
Background: Essential oil components (EOCs) are known for their antifungal properties; however, their high volatility limits their application as antimicrobial agents. Strategies used for controlling EOCs volatility include encapsulation or loading into porous materials. This study evaluated the in vitro antifungal activity of selected EOCs (carvacrol, cinnamaldehyde, eugenol and thymol) against the fungus Aspergillus niger when loaded into MCM-41 and $\beta$-cyclodextrin $(\beta$-CD).
\end{abstract}

Results: It was found that carvacrol and thymol in Mobil Composition of Matter No. 41 (MCM-41) display remarkable enhanced antifungal properties in comparison to the pure or $\beta$-CD-encapsulated EOCs. In fact, carvacrol and thymol were able to maintain antifungal activity and inhibit fungal growth for 30 days, suggesting better applicability of these EOCs as natural preservatives.

Conclusions: The sustained antifungal effect of EOCs encapsulated into silica mesoporous supports was described.

Keywords: essential oil components, encapsulation, mesoporous silica materials, cyclodextrin, controlled release, antifungal activity 


\section{INTRODUCTION}

One of the most important groups of bioactive natural compounds are essential oil components (EOCs). ${ }^{1-3}$ Since at least the Middle Ages these have been widely used for their antimicrobial, antiparasitic and insecticidal properties in various applications. ${ }^{4-6}$ On the contrary, in recent decades, the use of synthetic antimicrobials has taken the lead, partly because of the technological drawbacks of natural products, such as high volatility, reactivity and poor water solubility. These properties decrease their biological effect and limit their application in the agriculture, food and pharmaceutical industries. ${ }^{7}$ Now, due to consumers' preferences for natural chemicals, as well as new concerns about health and environmental safety of synthetic chemicals, essential oils and their components are again being proposed as natural antimicrobials in the aforementioned industries. In order to improve the conditions of use, and increase the applicability of natural antimicrobial formulations, encapsulation technologies are of great importance. ${ }^{8}$ Cyclodextrins (CDs) are cyclic oligosaccharides capable of forming inclusion complexes with many organic compounds, including essential oils and volatiles, or their components. These complexes are used in order to improve the physical and/or chemical stability, as well as to stabilize volatile compounds by reducing or eliminating any losses through evaporation. Research attributes these formations to intermolecular interactions. When complexes form, the physiochemical properties of the guests can also change significantly, which is then the basis of extensive industrial applications using CDs. ${ }^{9,10,11}$

Silica mesoporous supports (SMPS) ${ }^{12}$ have been used as inorganic scaffolds for the storage and release of drugs and organic molecules. ${ }^{13-16}$ Among the unique features of SMPS are high stability, biocompatibility, homogeneous porosity, high inertness and ease of functionalization. ${ }^{17}$ SMPS can be prepared in sizes from micrometric to 
nanometric with tailor-made pores of around 2-10 $\mathrm{nm}$. One of the most interesting features of these solids in relation to the encapsulation of natural antimicrobial formulations is that SMPS show a very large specific surface area (up to $1200 \mathrm{~m}^{2} \mathrm{~g}^{-1}$ ) and thus have a large loading capacity.

Previous studies have reported the use of CDs to encapsulate allyl isothiocyanate (AITC), cinnamon leaf, garlic and thyme essential oils in order to develop methods for the controlled release of these active molecules. ${ }^{18-20}$ In comparison, the use of SMPS ${ }^{21-24}$ to encapsulate bioactive natural compounds such as EOCs is very rare. ${ }^{25-29}$ In this context, no examples have been reported in which SMPS were used in order to avoid the fast evaporation or to prolong the activity of the loaded agents.

Here, we took these concepts into account and reported the preparation of nanometric SMPS loaded with four EOCs, selected to represent the major antimicrobial components present in the essential oils (carvacrol, cinnamaldehyde, eugenol and thymol) $30,31,32$, and studied their use as antifungal formulations against Aspergillus niger, an example of a common causative agent of agricultural diseases, as well as human aspergilosis in immunocompromised patients. ${ }^{33}$ For comparison, we also report the antifungal activity of the same EOCs encapsulated in $\beta$-CD and pure nonencapsulated EOCs.

\section{EXPERIMENTAL}

\section{Methods and chemicals}

In order to characterize the materials, the study employed thermogravimetric analysis (TGA), elemental analysis (EA), Fourier transform infrared spectroscopy (FT-IR), powder X-ray diffraction (XRD), transmission electron microscopy (TEM), scanning electron microscope (SEM), $\mathrm{N}_{2}$ adsorption-desorption and nuclear magnetic resonance 
(NMR). The thermogravimetric analyses were carried out on a TGA/SDTA 851e Mettler Toledo (Greifensee, Switzerland) balance using an oxidant atmosphere (air, 80 $\mathrm{mL} \min ^{-1}$ ) with a heating program consisting of a heating ramp of $10^{\circ} \mathrm{C}$ per minute from 393 to $1273 \mathrm{~K}$ and an isothermal heating step at this temperature for 30 minutes. The elemental analysis was performed in a CE Instrument EA-1110 CHN Elemental Analyzer (Wigan, UK). The near-IR spectra were recorded on a Jasco FT/IR-460 Plus instrument between 700 and $4000 \mathrm{~cm}^{-1}$, diluting the solids in $\mathrm{KBr}$ (Easton, Maryland, USA). Meanwhile, powder X-ray diffraction measurements were performed in a Bruker D8 Advance diffractometer using $\mathrm{Cu} \mathrm{K}_{\alpha}$ radiation (Billerica, Massachusetts, USA). The TEM images were obtained with a $100 \mathrm{kV}$ Philips CM10 microscope (JEOL, Tokyo, Japan). The SEM were performed with Hitachi S-450 and EDX (energy-dispersive Xray spectroscopy) detector Kevex Delta 5 (Chiyoda, Tokyo, Japan). Equilibrium adsorption isotherms of nitrogen were measured at $77 \mathrm{~K}$ using static volumetric adsorption systems (ASAP 2020 analyser, Micromeritic, Giorgia, USA). The adsorption isotherms were fitted to produce the BET surface area; the micropore volume was derived by the t-plot method and the pore size distribution by the BJH method. Before adsorption measurements, the sample was kept at $60{ }^{\circ} \mathrm{C}$ for $33 \mathrm{~h}$ under vacuum. In addition, 1H-NMR spectra were acquired with Bruker Avance I ${ }^{\mathrm{TM}} 400 \mathrm{MHz}$ equipment (Bruker BioSpin, Rheinstetten, Germany). The ${ }^{1} \mathrm{H}-\mathrm{NMR}$ studies were carried out in deuterium oxide.

The EOCs, carvacrol (98\%), cinnamaldehyde (99\%) and eugenol (99\%), were purchased from Sigma-Aldrich (St Louis, MO, USA) and thymol (99\%) was purchased from Fluka (St Louis, MO, USA). High-purity, Milli-Q water was used for all experiments. All other reagents used were of analytical grade. The chemicals tetraethyl orthosilicate (TEOS), n-cetyltrimethylammonium bromide (CTABr), sodium hydroxide 
$(\mathrm{NaOH}), 3$-aminopropyltriethoxysilane and triethanolamine (TEA) were purchased from Sigma-Aldrich (St Louis, MO, USA). $\beta$-CD (99\% purity) was purchased from Fluka (St Louis, MO, USA).

The tests were performed against A. niger ATCC 6275 (Czech Collection of Microorganisms, Brno, Czech Republic). Sabouraud Dextrose agar was used (Oxoid, Brno, Czech Republic) for the tests.

\section{Preparation of EOCs inclusion complexes with $\beta$-cyclodextrin}

$\beta$-CD-EOCs inclusion complexes were prepared using a coprecipitation method described by Bhandari et al. ${ }^{34}$ with minor modifications. $\beta$-CD $(500 \mathrm{mg})$ was dissolved in $15 \mathrm{~mL}$ of distilled water at $60{ }^{\circ} \mathrm{C}$. After cooling the $\beta$-CD solution to $40{ }^{\circ} \mathrm{C}$, EOCs in ethanol $(1: 1, \mathrm{v} / \mathrm{v})$ was slowly added to the solution with continuous agitation, to give a final molar ratio of EOCs $\beta-\mathrm{CD}^{-1}$ of 1 (66 mg of carvacrol, $58 \mathrm{mg}$ of cinnamaldehyde, $72 \mathrm{mg}$ of eugenol and $66 \mathrm{mg}$ of thymol with $500 \mathrm{mg}$ of $\beta$-CD). The vessel was sealed and stirred for $3 \mathrm{~h}$, after which the resulting slurry was refrigerated overnight at $4{ }^{\circ} \mathrm{C}$. The cold precipitate was recovered by vacuum-filtration and washed with $1.5 \mathrm{~mL}$ distilled water, and then dried in a vacuum oven at $75^{\circ} \mathrm{C}$ for $24 \mathrm{~h}$. The final dry complex powders were stored in an airtight glass desiccator at room temperature. Using this approach, the final inclusion complexes $\beta$-CD-Ca, $\beta$-CD-Ci, $\beta$-CD-Eu and $\beta$-CDThy (i.e $\beta$-cyclodextrin containing carvacrol, cinnamaldehyde, eugenol, and thymol, respectively) were prepared. 


\section{Synthesis of mesoporous MCM-41 microparticles}

The synthesis of MCM-41 was based on the use of TEA ligands as hydrolytic inorganic precursors and surfactants as porogen species. ${ }^{35}$ In a typical synthesis, $9.36 \mathrm{~g}$ of CTABr were added at $118^{\circ} \mathrm{C}$ to a solution of TEA $(52.4 \mathrm{~g})$ containing $0.98 \mathrm{~g}$ of $\mathrm{NaOH}$ in $2 \mathrm{~mL}$ of water and $0.098 \mathrm{~mol}$ of a silatrane derivative (e.g. $22 \mathrm{~mL}$ of TEOS was added at 70 ${ }^{\circ} \mathrm{C}$ to TEA). Then, $180 \mathrm{~mL}$ of deionized water were added while being vigorously stirred at $70{ }^{\circ} \mathrm{C}$. After a few minutes of stirring, a white suspension was formed. Using filtration, the resulting powder was collected and then it was washed with water and ethanol. Finally, the solid was dried at $70{ }^{\circ} \mathrm{C}$. To prepare the final porous material, the as-synthesized solid was calcinated at $550{ }^{\circ} \mathrm{C}$ for $5 \mathrm{~h}$ to remove the template phase.

\section{Synthesis of SMPS-EOCs}

Silica loading with EOCs was achieved via vapor adsorption by mixing each EOCs (40 $\mathrm{mg}$ ) with the MCM-41 silica solid (40 mg) in a tightly closed vial. The mixture was incubated in an oven at $40^{\circ} \mathrm{C}$ for $24 \mathrm{~h}$ while being continuously shaken. The amount of EOCs loaded in the MCM-41 support was determined by monitoring the sample weight increase and by TGA and elemental analysis studies. Using this approach, the final mesoporous materials SMPS-Ca, SMPS-Ci, SMPS-Eu and SMPS-Thy (loaded with carvacrol, cinnamaldehyde, eugenol, and thymol, respectively) were prepared.

\section{Antifungal assays}

Spore suspension was prepared by washing the A. niger culture with $2 \mathrm{~mL}$ sterile Tris Buffered Saline (TBS) containing $1 \%$ of Tween 80 and standardized to 1 McFarland (approx. $5 \times 10^{6}$ spores per $\mathrm{mL}$ ). The $300 \mu \mathrm{L}$ of sterile TBS and $50 \mu \mathrm{L}$ of the spore suspension were added to the Eppendorf tubes containing the different EOCs 
formulations. All the mixtures were then vigorously vortexed to ensure complete suspension and immediately spread onto Petri dishes which contained Sabouraud Dextrose agar (SDA). The petri dishes were not sealed in order to allow the vapors to escape. Next, growth control, EOCs encapsulated into SMPS, $\beta$-CD and pure EOCs were tested in triplicate. These tests were realized with similar amount $(0.5 \mathrm{mg})$ of EOCs: i.e. $0.5 \mathrm{mg}$ of pure EOCs, $5 \mathrm{mg}$ of $\beta$-CD complexes and $1 \mathrm{mg}$ of MCM-41 solids.

Monitoring was done for one month by visual inspection and by taking photographs with a digital camera under standard light conditions with a white background on days 2, 6, 15 and 30. The experiment was evaluated via the analysis of the luminosity of each picture of the Petri dish in a function of time. The value of relative luminosity was calculated by dividing the luminosity of each sample by the luminosity of the growth control (without any EOCs) on that particular day. All the pictures taken during the experiment were analyzed with Zoner Photo Studio software (Zoner Software a.s., Czech Republic). The evaluation was carried out in triplicates and standard deviation was calculated for each sample. 


\section{RESULTS AND DISCUSSION}

\section{The cyclodextrin materials}

$\beta$-CD-EOCs were obtained by mixing each EOCs with the $\beta$-CD. To determine the amount of EOCs in the final isolate complexes, elemental analysis was carried out and the results are shown in Table 1.

Table 1. Content $(\alpha)$ in grams of EOCs per kilogram of $\beta$-CD for solids $\beta$-CD, $\beta$-CD$\mathrm{Ca}, \beta$-CD-Ci, $\beta$-CD-Eu and $\beta$-CD-Thy and content $(\alpha)$ in grams (average using TGA and EA) of EOCs per kilogram of solid for solids MCM-41, SMPS-Ca, SMPS-Ci, SMPS-Eu and SMPS-Thy. BET Specific Surface Values, Pore Volumes and Pore Sizes Calculated from the $\mathrm{N}_{2}$ Adsorption-Desorption Isotherms for selected materials. ${ }^{a}$ Pore volumes are associated with the value of single point adsorption total pore volume of pores. ${ }^{b}$ Pore size is average pore size estimated by using the BJH model applied on the adsorption branch of the isotherm and it is only associated with intraparticle mesopores in the case of MCM-41 and intraparticle and interparticle mesopores in the case of SMPS-EOCs.

\begin{tabular}{|ccccc|}
\hline Solids & $\begin{array}{c}\alpha_{E O C s} \\
\left(\mathrm{~g} \mathrm{~kg}^{-1}\right)\end{array}$ & $\begin{array}{c}S_{B E T} \\
\left(\mathrm{~m}^{2} \mathrm{~g}^{-1}\right)\end{array}$ & $\begin{array}{c}\text { Pore Volume }^{\mathrm{a}} \\
\left(\mathrm{cm}^{3} \mathrm{~g}^{-1}\right)\end{array}$ & $\begin{array}{c}\text { Pore size }^{\mathrm{b}} \\
(\mathrm{nm})\end{array}$ \\
\hline \hline MCM-41 & - & 1437.29 & 0.84 & 2.29 \\
SMPS-Ca & 476 & 683.00 & 0.32 & 3.37 \\
SMPS-Ci & 537 & 450.24 & 0.23 & 6.14 \\
SMPS-Eu & 516 & 278.88 & 0.16 & 7.27 \\
SMPS-Thy & 496 & 51.56 & 0.063 & 24.6 \\
$\beta$-CD-Ca & 112 & - & - & - \\
$\beta$-CD-Ci & 103 & - & - & - \\
$\beta$-CD-Eu & 125 & - & - & - \\
$\beta$-CD-Thy & 98 & - & - & - \\
\hline
\end{tabular}

$\alpha$ : organic content in grams of EOCs per kilogram of empty $\beta$-CD or SMPS. EOCs: essential oil components. $\beta$-CD: $\beta$-cyclodextrin. SMPS: silica mesoporous supports. MCM-41: Mobil composition of

Matter No. 41. $\mathrm{S}_{B E T}$ : specific surface values. EOCs: essential oil components. $\beta$-CD: $\beta$-cyclodextrin. SMPS: silica mesoporous supports. MCM-41: Mobil composition of Matter No. 41. 
The IR spectra of $\beta$-CD-Ca, $\beta$-CD-Ci, $\beta$-CD-Eu and $\beta$-CD-Thy complexes as well as that of the $\beta$-CD alone are shown in Figure 1A. The dominant bands in all spectra are due to the $\beta$-CD $\left(2925,1680-1650,1200\right.$ and $\left.1100 \mathrm{~cm}^{-1}\right)$ and those related to the vibrations of water molecules (3420 and $\left.1650 \mathrm{~cm}^{-1}\right)$. Moreover, some characteristic $\mathrm{C}-\mathrm{H}$ and $\mathrm{C}=\mathrm{C}$ stretching vibrations in the ca. $3000-2900 \mathrm{~cm}^{-1}$ and $1600-1450 \mathrm{~cm}^{-1}$ range, respectively, were also observed and confirmed the existence of the inclusion complexes. In the case of the $\beta$-CD-Ci solid, an intense $\mathrm{C}=\mathrm{O}$ band at $1645 \mathrm{~cm}^{-1}$ due to the aldehyde group is also observed. Figure 1B shows the XRD patterns of the $\beta$-CD solid and that of $\beta$-CD-Eu. The X-ray diffraction pattern of both solids is clearly different, strongly suggesting the formation of inclusion complexes between Eu and $\beta$ CD. The SEM analysis shows a clear difference between the morphology and shape of $\beta$-CD crystals and those of the $\beta$-CD-Eu complex (see Figure 2). To complete the characterization we carried out ${ }^{1} \mathrm{H}-\mathrm{NMR}$ studies (see Supporting Information). As it can be seen, the spectrum of $\beta$-CD-Eu displays similar signals to those found for $\beta$-CD in the 4-3.6 ppm and typical aromatic resonances of pure eugenol in the 6-7 ppm range. 
A

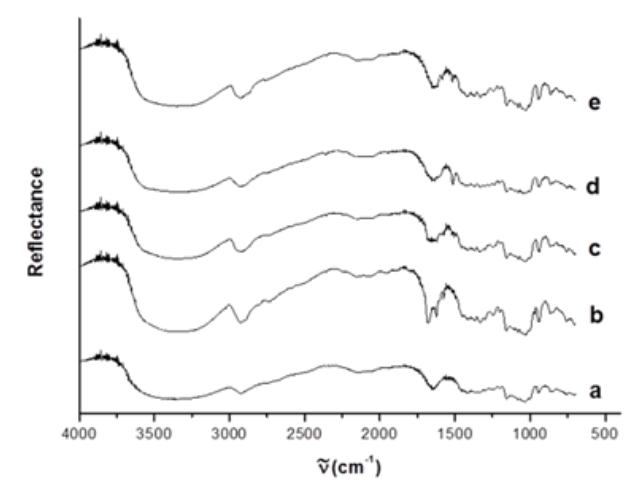

B

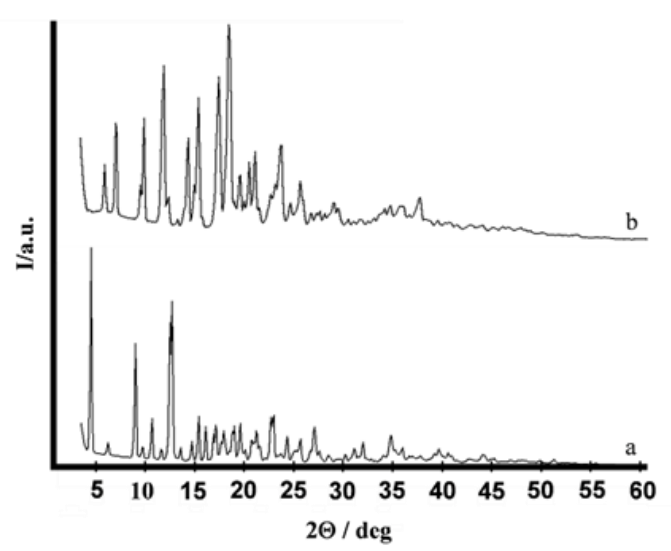

Figure 1. (A) IR spectroscopy of the solids (a) $\beta$-CD, (b) $\beta$-CD-Ca, (c) $\beta$-CD-Ci, (d) $\beta$ CD-Eu and (e) $\beta$-CD-Thy. (B) Powder X-ray patterns of the solids (a) $\beta$-CD and the final solid (b) containing eugenol.

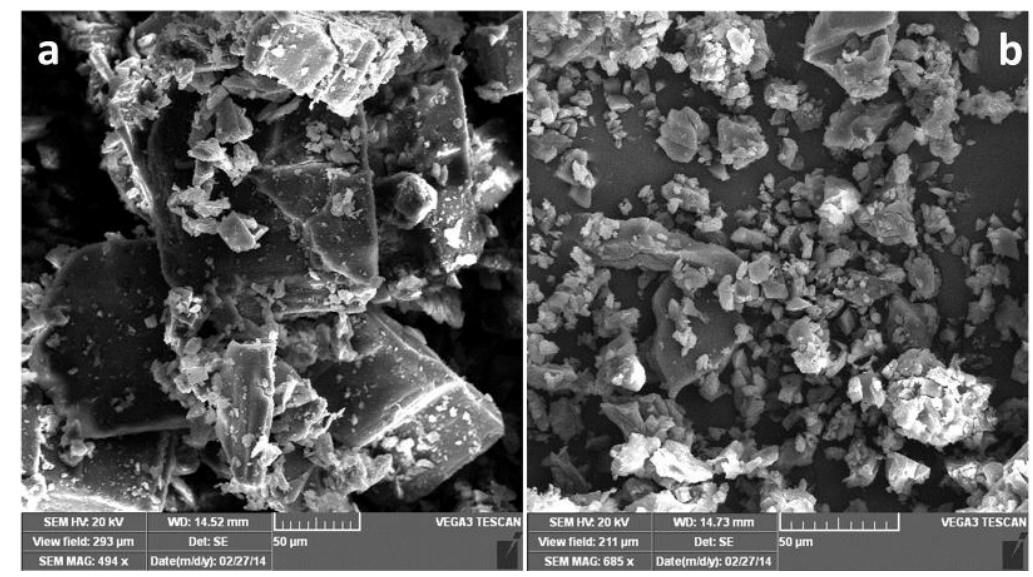

Figure 2. SEM image of (a) $\beta$-CD and solid (b) $\beta$-CD-Eu showing the typical structure of the cyclodextrin complex. 


\section{The silica materials}

The solids EOCs-SMPS were obtained by reaction of the corresponding EOCs with the MCM-41 material. The amount of EOCs entrapped in the MCM-41 material was analyzed via weight differences before and after the loading process. In all cases ca. 500 $\mathrm{g} \mathrm{kg}^{-1}$ of the final weight corresponded to EOCs (see Supporting Information). In addition, these loadings were corroborated by the TGA and elemental analysis studies (see Table 1); this loading capacity was higher than other encapsulation techniques that were reviewed. ${ }^{36}$

In Figure $3 \mathrm{~A}$ the IR spectrum of all the solids is shown. The dominant bands in all supports are due to the silica matrix $\left(1250,1087\right.$ and $\left.802 \mathrm{~cm}^{-1}\right)$ and those related to the vibrations of water molecules $\left(3420\right.$ and $\left.1620 \mathrm{~cm}^{-1}\right)$. Moreover, for the materials loaded with EOCs characteristic $\mathrm{C}-\mathrm{H}$ and $\mathrm{C}=\mathrm{C}$, stretching vibrations in the $3000-2900 \mathrm{~cm}^{-1}$ and $1600-1450 \mathrm{~cm}^{-1}$ ranges, respectively, are clearly observed. Furthermore, in the case of the SMPS-Ci solid an intense $\mathrm{C}=\mathrm{O}$ band at $1645 \mathrm{~cm}^{-1}$ due to the presence of an aldehyde group is also found. Figure 3B shows the powder X-Ray diffraction (XRD) patterns of the solids MCM-41 as synthesized, MCM-41 calcined and SMPS-Eu. The XRD of MCM-41 as-synthesized (curve a) shows the typical low-angle reflections of a hexagonal ordered array. In curve b, corresponding to the MCM-41 calcined sample, a significant shift of the reflections in the XRD is clearly observed. This displacement is consistent with an approximate cell contraction and attributed to the condensation of silanol groups during the calcination step. The reflections of the solid SMPS-Eu are practically lost due to the presence of eugenol on the pores. The TEM in the SMPS-Eu solid shows the typical channels of the MCM-41 matrix are visualized as alternate black and white stripes (Figure 4). Moreover the SEM images (see Figure 4) show the 
microparticle structure of the SMPS-Eu support. Similar XRD, TEM and SEM images to that found for SMPS-Eu were observed for solids SMPS-Ca, SMPS-Ci and SMPSThy (data not shown). The $\mathrm{N}_{2}$ adsorption-desorption isotherms of the starting MCM-41 material and SMPS-Eu are shown in Figure 5. The typical curve for these mesoporous solids consisting of an adsorption step at intermediate $\mathrm{P} / \mathrm{P} 0$ values can be observed and the isotherms of SMPS-Eu curves of mesoporous systems with partially filled mesopores. $^{37,38}$ Moreover, Table 1 displays the BET specific surface values, pore volumes and pore sizes calculated for all the solids. These values indicate significant pore blocking and the subsequent absence of appreciable mesoporosity.

A

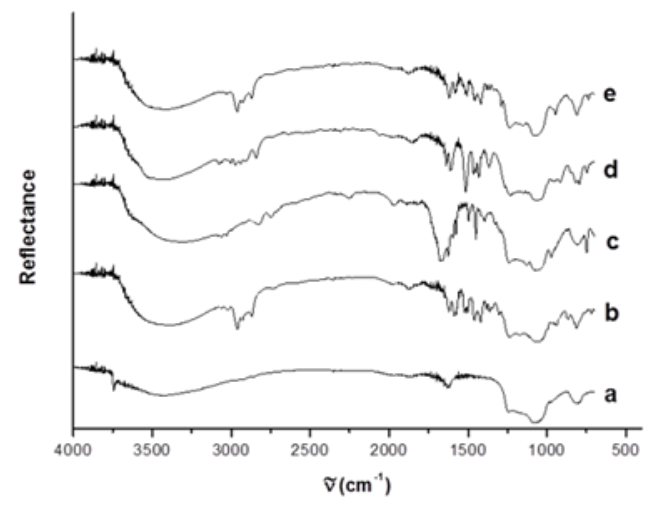

B

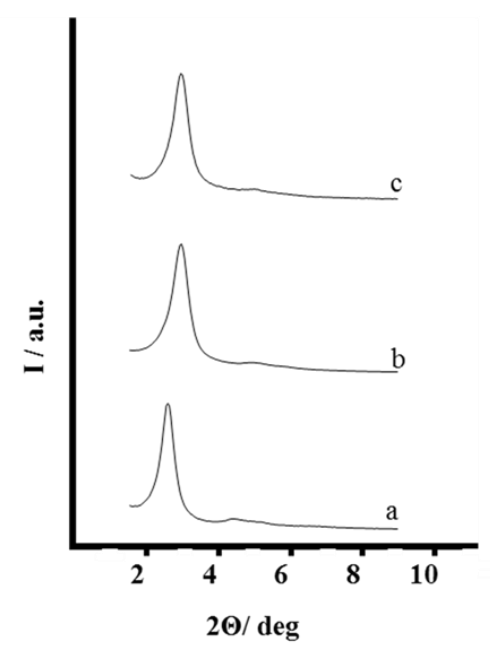

Figure 3. (A) IR spectroscopy of the solids: (a) MCM-41 calcined, (b) SMPS-Ca, (c) SMPS-Ci, (d) SMPS-Eu and (e) SMPS-Thy. (B) Powder X-ray patterns of the solids (a) MCM-41 as-synthesized, (b) MCM-41 calcined, and the final solid (c) containing eugenol. 

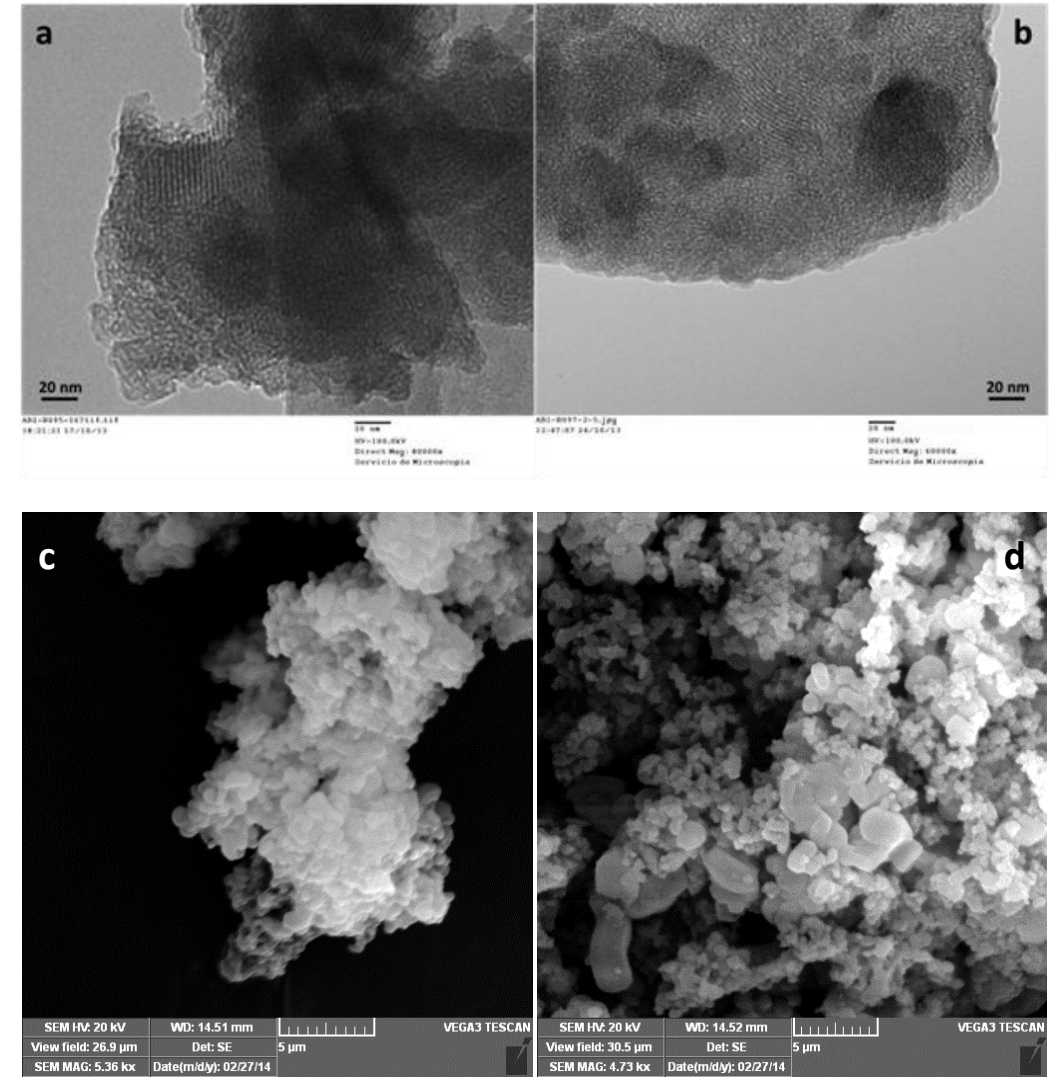

Figure 4. TEM image of (a) MCM-41 calcined and (b) solid SMPS-Eu showing the typical hexagonal porosity of the MCM-41 matrix and SEM image of (c) MCM41calcined and (d) solid SMPS-Eu showing the typical structure of the MCM-41 microparticulate.
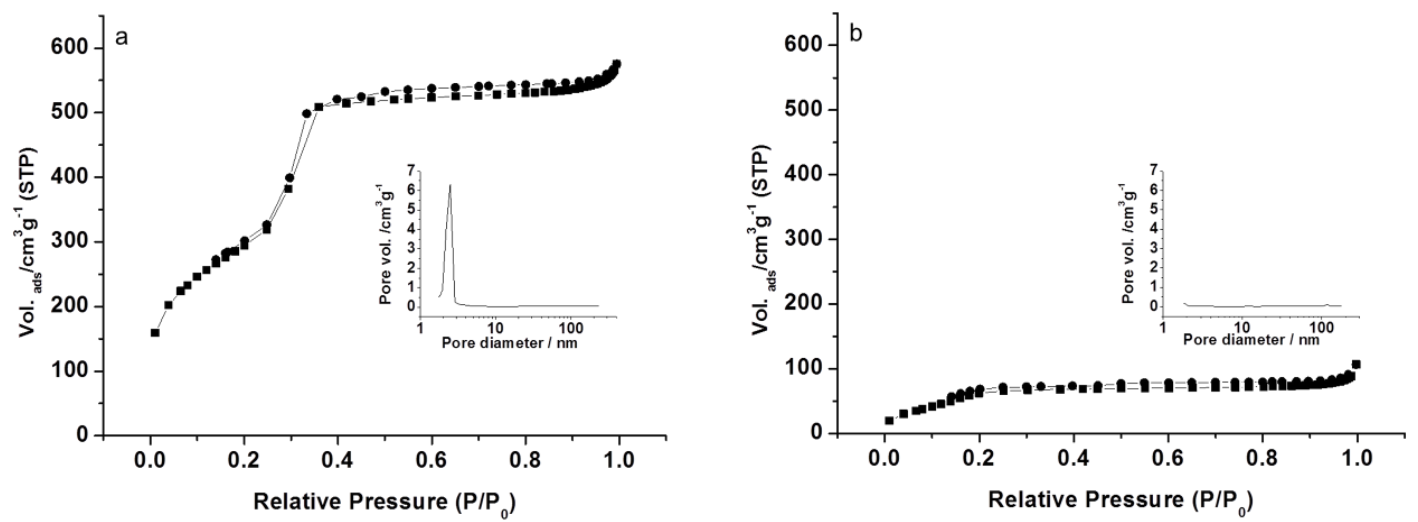

Figure 5. Nitrogen adsorption-desorption isotherms for (a) MCM-41 mesoporous material and (b) SMPS-Eu material. Insets: Pore size distribution of each material. 


\section{Antifungal assay}

Monitoring of the antifungal properties was carried out for one month and the evaluation of the relative luminosity was analyzed. When the growing fungi was present, the luminosity was decreased. The luminosity of the sample was divided by the luminosity of the control. This means that the growth control exhibited the lowest luminosity (the relative luminosity value was always 1) while the samples with higher antifungal activity show higher relative luminosity. The initial effect of the EOCs on the growth of $A$. niger was not obvious, hence after 2 days all systems displayed quite a low relative luminosity, indicating that there were no significant differences in comparison to the control. After 6 days of exposure, the most active formulation was SMPS-Thy, SMPS-Ca and pure thymol; in all cases a relative luminosity of approximately 3 was observed. At day 15 there was a clear antifungal effect in the presence of SMPS-Thy and SMPS-Ca, whereas the remaining formulations maintained a very low relative luminosity. This enhanced antifungal activity for SMPS-Thy and SMPS-Ca with respect to the other tested systems was even more notable after one month. After one month, all the $\beta$-CD-EOCs systems, together with the SMPS-Eu and SMPS-Ci, showed relative luminosity lower than 2 units, and all the pure EOCs showed lower than 3 units. Meanwhile, the solids SMPS-Ca and SMPS-Thy displayed a relative luminosity of more than 6 units (Figure 6). This remarkable result indicates that after 30 days, carvacrol and thymol essential oils encapsulated in MCM-41 maintained antifungal activity and inhibited fungal growth. 

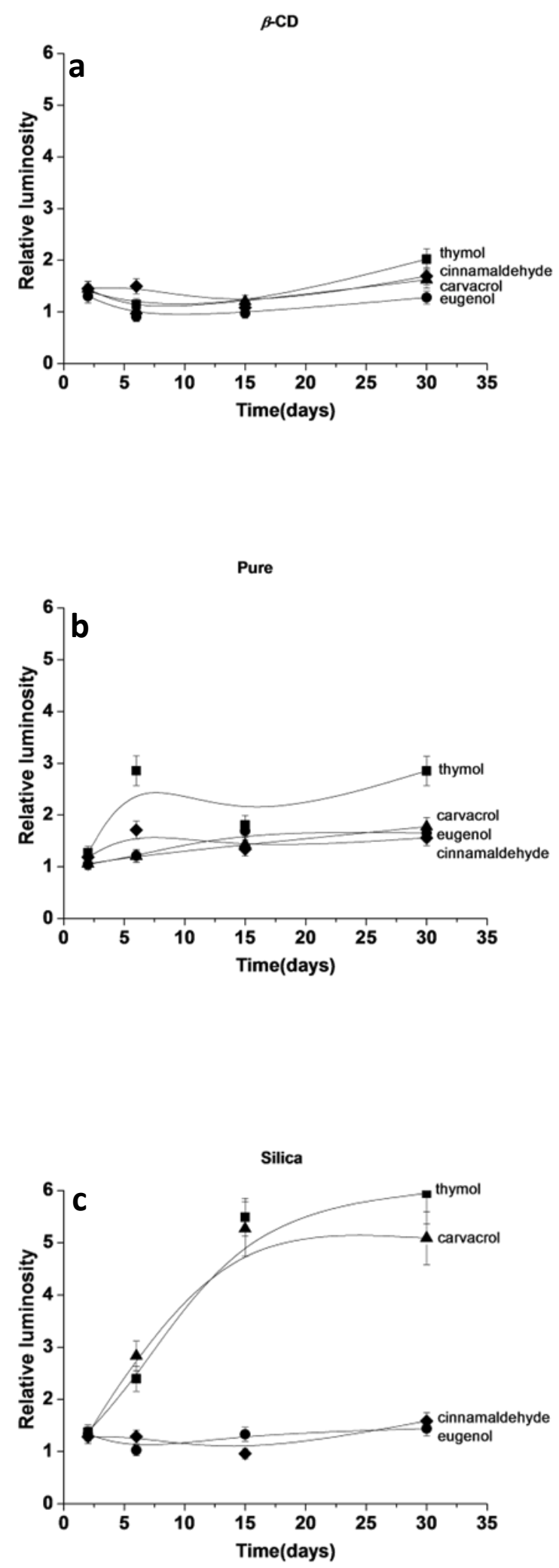

Figure 6. Fungal growth inhibition (relative luminosity) of EOCs encapsulated in $\beta$-CD (a). Fungal growth inhibition (relative luminosity) of pure EOCs (b). Fungal growth inhibition (relative luminosity) of EOCs encapsulated in silica (c). 
In case of $\beta$-CD-EOCs, there was no significant antifungal effect. The reason could be the low availability of the active compounds in this type of encapsulation, or that $\beta$-CD itself increased the mycelial growth of $A$. niger because $\beta$-CD acts as a carbohydrate source for the fungus. ${ }^{19}$ In the literature there are few examples in which the controlled release of antifungal volatile compounds from $\beta$-CD was studied. ${ }^{18}$ One of these studies involved the formation of inclusion complexes with thyme essential oil. ${ }^{19}$ The latter study showed antifungal activity after 48 hours, with a markedly lower activity of encapsulated essential oil compared to pure oil. However, the study did not describe the possibility of a sustained inhibition of fungal growth.

EOCs such as carvacrol, cinnamaldehyde, eugenol and thymol are well known for their antimicrobial activity, ${ }^{30-32}$ but in the case of SMPS-Ci and SMPS-Eu we have observed lower antifungal effect compared to SMPS-Thy and SMPS-Ca. The reason of the difference in their antifungal activity could be the minimum inhibitory concentration (MIC). In the literature, some authors described that the MIC of eugenol is higher than thymol and carvacrol. Abbaszadeh et al. indicated in their results that all compounds tested were effective to varying extents against various fungal isolates, with the highest efficacy displayed by carvacrol and thymol. ${ }^{39}$ The increased concentrations of eugenol led to progressive and significant reduction in growth for all fungi, but for the dose in our study $(0.5 \mathrm{mg})$ eugenol was not able to reduce the fungal growth. Bisht et al. tested antifungal activity of essential oils against Aspergillus flavus and Aspergillus niger. In their study, Origanum vulgare essential oil (thymol and carvacrol were the most abundant monoterpenes) exhibited the highest activity if compared with Cinnamomum tamala leaf oil (cinnamladehyde as the principal component). ${ }^{40}$ This is probably the main reason, why we obtained lower antifungal effect in the case of cinnamaldehyde and eugenol encapsulated in MCM-41 compared to SMPS-Thy and SMPS-Ca. 
As stated above, this work aimed to develop delivery systems using mesoporous scaffolds for the sustained antifungal activity of EOCs. Various delivery systems have been proposed for their capability of decreasing volatility and improving the stability and water solubility to maintain the antifungal efficacy, ${ }^{41}$ but in the majority of the published studies, it was not possible to obtain long term inhibition of fungal growth. Some previous studies have described the encapsulation of bioactive natural compounds in mesoporous materials, ${ }^{21-24}$ but the particular entrapment of EOCs and biological assays have barely been studied. Chen et al. developed a new nanophase material loaded with the biological pesticide Pyoluteorin and the bioactivity experiment showed prolonged antifungal effects compared with pure pesticide, but only for 4 days. ${ }^{23}$ In this context, it has been found that the antimicrobial properties of allylisothiocyanate (AITC) were unaffected by encapsulation into SMPS, resulting in a reduction of bacteria similar to that found with pure AITC vapors, but also without any prolonged or sustained activity. ${ }^{26,27}$ Other results from Usha Rani et al. suggested that the antifeedant activity of the $\alpha$-pinene and linalool was enhanced by formulation with silica nanoparticles and bioactivity was correlated with the concentration of these compounds in the formulations. Adsorption of the terpenes on the surface of the nanoparticles enables even distribution resulting in increased bioavailability of the compounds. ${ }^{28}$ In our work, we have described the particular entrapment of EOCs inside SMPS and we demonstrated that EOCs absorption into the SMPS is able to generate a suitable carrier to improve the antimicrobial activity of EOCs, even 30 days after the treatment. 


\section{CONCLUSIONS}

In summary, we have reported herein a study of the in vitro antifungal activity against A. niger of certain EOCs (i.e. carvacrol, cinnamaldehyde, eugenol, and thymol) when encapsulated in MCM-41. Our study revealed that, even after 30 days, carvacrol and thymol encapsulated in mesoporous scaffolds were able to maintain antifungal activity and inhibit fungal growth. This is in clear contrast with the corresponding compounds when alone or encapsulated in $\beta$-CD; none of these were able to display antifungal properties to such extent. To the best of our knowledge, this is the first report that demonstrates that the antifungal behavior of these EOCs is enhanced via their entrapment in mesoporous supports.

\section{ABREVIATIONS AND NOMENCLATURE}

EOCs: Essential oil components

$\beta$-CD: $\beta$-cyclodextrin

SMPS: silica mesoporous supports

MCM-41: Mobil composition of Matter No. 41

A. niger: Aspergillus niger

TGA: thermogravimetric analysis

EA: elemental analysis

FT-IR: Fourier transform infrared spectroscopy

XRD: powder X-ray

TEM: transmission electron microscopy 
SEM: scanning electron microscope

NMR: nuclear magnetic resonance

SMPS-Ca: carvacrol in silica

SMPS-Ci: cinnamaldehyde in silica

SMPS-Eu: eugenol in silica

SMPS-Thy: thymol in silica

$\beta$-CD-Ca: carvacrol in $\beta$-cyclodextrin

$\beta$-CD-Ci: cinnamaldehyde in $\beta$-cyclodextrin

$\beta$-CD-Eu: eugenol in $\beta$-cyclodextrin

$\beta$-CD-Thy: thymol in $\beta$-cyclodextrin

MIC: Minimum inhibitory concentration

\section{ACKNOWLEDGMENTS}

The authors wish to express their gratitude to the Government of the Czech Republic (Postdok ČZU: ESF and MEYS CZ.1.07/2.3.00/30.0040), to CIGA (Project number: 20132024) and to the Institute of Organic Chemistry and Biochemistry, Academy of Sciences of the Czech Republic (research project RVO: 61388963). Also we wish to thank Beth Green for language control. 


\section{SUPPORTING INFORMATION}

The authors wish to include six figures: the structure of each of the EOCs; the schematic representations of the synthesis of $\beta$-CD-EOCs and SMPS-EOCs; the ${ }^{1} \mathrm{H}-\mathrm{NMR}$ spectrum of $\beta$-CD, pure eugenol and $\beta$-CD-Eu in $\mathrm{D}_{2} \mathrm{O}$; the Nitrogen adsorptiondesorption isotherms for SMPS-Ca, SMPS-Ci and SMPS-Thy mesoporous materials; and a figure showing the $\beta$-CD pure and silica pure after few days with fungi: $2 / 6 / 15 / 30$ days.

\section{REFERENCES}

1. Cavanagh HMA, Antifungal activity of the volatile phase of essential oils: A brief review. Nat Prod Comm 2(12): 1297-1302 (2007).

2. Tajkarimi MM, Ibrahim SA and Cliver DO, Antimicrobial herb and spice compounds in food. Food Control 21(9): 1199-1218 (2010).

3. Nedorostova L, Kloucek P, Kokoska L, Stolcova M and Pulkrabek J, Antimicrobial properties of selected essential oils in vapour phase against foodborne bacteria. Food Control 20(2): 157-160 (2009).

4. Havlik J, Budesinsky M, Kloucek P, Kokoska L, Valterova I, Vasickova S and Zeleny V, Norsesquiterpene hydrocarbon, chemical composition and antimicrobial activity of Rhaponticum carthamoides root essential oil. Phytochem 70(3): 414-418 (2009).

5. Kloucek P, Smid J, Frankova A, Kokoska L, Valterova I and Pavela R, Fast screening method for assessment of antimicrobial activity of essential oils in vapor phase. Food Re Int 47(2): 161-165 (2012). 
6. Bakkali F, Averbeck S Averbeck D and Waomar M, Biological effects of essential oils - A review. Food Chem Toxicol 46(2): 446-475 (2008).

7. Laird K and Phillips C, Vapour phase: a potential future use for essential oils as antimicrobials? Lett Appl Microbio 54(3): 169-174 (2012).

8. Liu H, Yang G, Tang Y, Cao D, Qi T, Qi Y and Fan G, Physicochemical characterization and pharmacokinetics evaluation of $\beta$-caryophyllene/ $\beta$-cyclodextrin inclusion complex. Int J Pharm 450: 304-310 (2013).

9. Hedges AR, Industrial applications of cyclodextrins. Chem Rev 98(5): 2035-2044 (1998).

10. Liu L, Song KS, Li XS and Guo QX, Charge-transfer interaction: A driving force for cyclodextrin inclusion complexation. J Incl Phen Macro Chem 40(1-2): 35-39 (2001).

11. Tavornvipas S, Arima H, Hirayama F, Uekama K, Ishiguro T, Oka M, Hamayasu K and Hashimoto H, Some pharmaceutical properties of a new branched cyclodextrin, 6-O-alphas-(4-O-alpha-D-glucuronyl)-D-glucosyl-beta-cyclodextrin. J Incl Phen Macro Chem 44(1-4): 391-394 (2002).

12. Kresge CT, Leonowicz ME, Roth WJ, Vartuli JC and Beck JS, Ordered mesoporous molecular sieves synthesized by a liquid-crystal template mechanism. Nature 359(6397): 710-712 (1992).

13. Schmaljohann D, Thermo- and $\mathrm{pH}-$ responsive polymers in drug delivery. Adv Drug Deliv Rev 58(15): 1655-1670 (2006). 
14. Vallet-Regí M, Balas F and Arcos D, Mesoporous materials for drug delivery. Ang Chem Int Ed 46(40): 7548-7558 (2007).

15. Vallet-Regí M, Rámila A, del Real RP and Pérez-Pariente J, A new property of MCM-41: Drug delivery system. Chem Mater 13: 308-311 (2001).

16. He D, He X, Wang K, Zou Z, Yang X and Li X, Remote-controlled drug release from graphene oxide-capped mesoporous silica to cancer cells by photoinduced $\mathrm{pH}$ jump activation. Langmuir 30 (24): $7182-7189$ (2014).

17. Muñoz B, Rámila A, Pérez-Pariente J, Díaz I, and Vallet-Regí M, MCM-41 organic modification as drug delivery rate regulator. Chem Mater 15(2): 500-503 (2003).

18. Li X, Jin Z and Wang J, Complexation of allyl isothiocyanate by $\alpha$ - and $\beta$ cyclodextrin and its controlled release characteristics. Food Chem 103(2): 461-466 (2007).

19. del Toro-Sánchez CL, Ayala-Zavala JF, Machi L, Santacruz H, Villegas-Ochoa MA, Álvarez-Parrilla E and González-Aguilar GA, Controlled release of antifungal volatiles of thyme essential oil from $\beta$-cyclodextrin capsules. J Incl Phen Macro Chem 67(3-4): 431-441 (2010).

20. Marques HMC, A review on cyclodextrin encapsulation of essential oils and volatiles. Flav Frag J 25(5): 313-326 (2010).

21. Clifford NW, Iyer KS and Raston CL, Encapsulation and controlled release of nutraceuticals using mesoporous silica capsules. J Mat Chem 18(2): 162-165 (2008). 
22. Prado AGS, Moura AO and Nunes AR, Nanosized silica modified with carboxylic acid as support for controlled release of herbicides. J Agr Food Chem 59(16): 8847$8852(2011)$.

23. Chen J, Wang W, Xu Y and Zhang X, Slow-release formulation of a new biological pesticide, pyoluteorin, with mesoporous silica. J Agr Food Chem 59(1): 307-311 (2011).

24. Siahaan EA, Meillisa A, Woo HC, Lee CW, Han JH and Chun BS, Controlled release of allyl isothiocyanate from brown algae Laminaria japonica and mesoporous silica MCM-41 for inhibiting food-borne bacteria. Food Sci Biotechnol 22: 19-24 (2013).

25. Bernardos A and Kourimska L, Applications of mesoporous silica materials in food-a review. Czech J Food Sci 31(2): 99-107 (2013).

26. Park SY and Pendleton P, Mesoporous silica SBA-15 for natural antimicrobial delivery. Powder Technol 223: 77-82 (2012).

27. Park SY, Barton M and Pendleton P, Controlled release of allyl isothiocyanate for bacteria growth management. Food Control 23(2): 478-484 (2012).

28. Usha Rani P, Madhusudhanamurthy J and Sreedhar B, Dynamic adsorption of $\alpha$ pinene and linalool on silica nanoparticles for enhanced antifeedant activity against agricultural pests. J Pest Sc 87: 191-200 (2014).

29. Lai F, Wissing SA, Müller RH and Fadda AM, Artemisia arborescens L essential oil-loaded solid lipid nanoparticles for potential agricultural application: preparation and characterization. AAPS Pharm Sci Tech 7(1): Article 2 (2006). 
30. Lopez-Malo A, Alzamora SM and Palou E, Aspergillus flavus dose-response curve to select natural and synthetic antimicrobials. Int J Food Microbiol 73, 213-218 (2002).

31. Xu S, Yan F, Ni Z, Chen Q, Zhang $\mathrm{H}$ and Zheng $\mathrm{X}$, In vitro and in vivo control of Alternaria alternata in cherry tomato by essential oil from Laurus nobilis of Chinese origin. J Sci Food Agric 94: 1403-1408 (2014).

32. Wang SY, Chen PF and Chang ST, Antifungal activities of essential oils and their constituents from indigenous cinnamon (Cinnamomum osmophloeum) leaves against wood decay fungi. Bioresour Technol 96: 813-818 (2005).

33. Kumar R, Tiwari OP, Dubey NK, Tripathi YB and Sinha KK, Evaluation of some essential oils as botanical fungitoxicants for the protection of stored food commodities from fungal infestation. J Sci Food Agric 87(9): 1737-1742 (2007).

34. Bhandari BR, D'arcy BR and Bich LLT, Lemon oil to $\beta$-cyclodextrin ratio effect on the inclusion efficiency of $\beta$-cyclodextrin and the retention of oil volatiles in the complex. J Agr Food Chem 46(4): 1494-1499 (1998).

35. Cabrera S, El Haskouri J, Guillem C, Latorre J, Beltrán D, Marcos MD and Amorós P, Generalised syntheses of ordered mesoporous oxides: the atrane route. Solid State Sci 2(4): 405-420 (2000).

36. Fang Z and Bhandari B, Encapsulation of polyphenols - a review. Tr Food Sci Tech 21(10): 510-523 (2010).

37. Barrett EP, Joyner LG and Halenda PP, The Determination of pore volume and area distributions in porous substances. I. Computations from nitrogen isotherms. $J$ Am Chem Soc 73(1): 373-380 (1951). 
38. Brunauer S, Emmett PH and Teller E, Adsorption of gases in multimolecular layers. J Am Chem Soc 60(2): 309-319 (1938).

39. Abbaszadeha S, Sharifzadehb A, Shokric H, Khosravib AR and Abbaszadehd A, Antifungal efficacy of thymol, carvacrol, eugenol and menthol as alternative agents to control the growth of food-relevant fungi. J Mycol Med 24(2): e51-e56 (2014).

40. Bisht D, Pal A, Chanotiya CS, Mishra D and Pandey KN, Terpenoid composition and antifungal activity of three commercially important essential oils against Aspergillus flavus and Aspergillus niger. Nat Prod Res 25(20): 1993-1998 (2011).

41. Bilia AR, Guccione C, Isacchi B, Righeschi C, Firenzuoli F and Bergonzi MC, Essential oils loaded in nanosystems: a developing strategy for a successful therapeutic approach. J Evid Based Complementary Altern Med 2014: 651593 (2014). 


\section{ANTIFUNGAL EFFECT OF ESSENTIAL OIL COMPONENTS AGAINST ASPERGILLUS NIGER WHEN LOADED INTO SILICA MESOPOROUS SUPPORTS}

Andrea Bernardos ${ }^{\mathrm{a}}$, Teresa Marina ${ }^{\mathrm{b}}$, Petr Žáček ${ }^{\mathrm{c}}$, Édgar Pérez-Esteve ${ }^{\mathrm{d}, \mathrm{e}}$, Ramón Martínez-Mañez ${ }^{\mathrm{d}, \mathrm{f}}$, Miloslav Lhotka ${ }^{\mathrm{g}}$, Lenka Kouřimská ${ }^{\mathrm{b}}$, Josef Pulkrábek ${ }^{\mathrm{a}}$, Pavel Klouček $^{\text {b,* }}$

${ }^{a}$ Department of Crop Production, Faculty of Agrobiology, Food and Natural Resources, Czech University of Life Sciences Prague, Kamýcká 129, Prague 6-Suchdol, 165 21, Czech Republic.

${ }^{b}$ Department of Quality of Agricultural Products, Faculty of Agrobiology, Food and Natural Resources, Czech University of Life Sciences Prague, Kamýcká 129, Prague 6-Suchdol, 165 21, Czech Republic.

${ }^{c}$ Research Team of Infochemicals, Institute of Organic Chemistry and Biochemistry. Academy of Sciences of the Czech Republic. Flemingovo nám. 2, 16610 Prague 6. Czech Republic.

${ }^{d}$ Centro de Reconocimiento Molecular y Desarrollo Tecnológico (IDM), Unidad Mixta Universitat Politècnica de València - Universitat de València, Camino de Vera s/n, E-46022 Valencia, Spain.

${ }^{e}$ Grupo de Investigación e Innovación Alimentaria (CUINA), Universitat Politècnica de València, Camino de Vera s/n, E-46022 Valencia, Spain.

${ }^{f}$ CIBER de Bioingeniería, Biomateriales y Nanomedicina (CIBER-BBN). Monforte de Lemos 35, Pabellón 11,28029, Madrid, Spain.

${ }^{g}$ Department of Inorganic Technology, Faculty of Chemical Technology, Institute of Chemical Technology, Technická 5, 16628, Prague 6, Czech Republic

Correspondence to Pavel Klouček: E-mail: kloucek@af.czu.cz;

phone: +420224382536 ; fax: +420224382535 . 


\section{Figure captions}

Figure SI-1. Structure of all the EOCs.<smiles>Cc1ccc(C(C)C)cc1O</smiles>

carvacrol<smiles>O=CC=Cc1ccccc1</smiles>

cinnamaldehyde<smiles>C=CCc1ccc(O)c(OC)c1</smiles><smiles>Cc1ccc(C(C)C)c(O)c1</smiles>

thymol

Figure SI-2. Schematic representation of the synthesis of $\beta$-CD-EOCs.
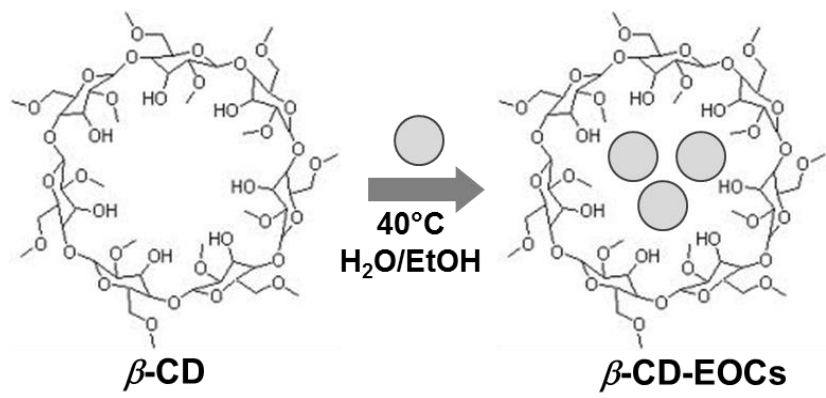

$\bigcirc$ Essential oil components

Figure SI-3. Schematic representation of the synthesis of mesoporous microparticles SMPS-EOCs.

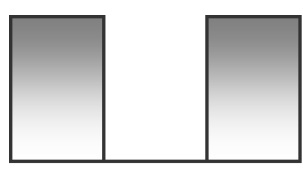

MCM-41

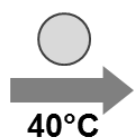

$40^{\circ} \mathrm{C}$

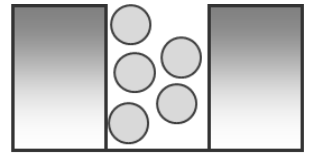

SMPS-EOCs

$\longrightarrow$ Essential oil components 
Figure SI-4. ${ }^{1} \mathrm{H}-\mathrm{NMR}$ spectrum of (a) $\beta$-CD, (b) pure eugenol and (c) $\beta$-CD-Eu in $\mathrm{D}_{2} \mathrm{O}$.
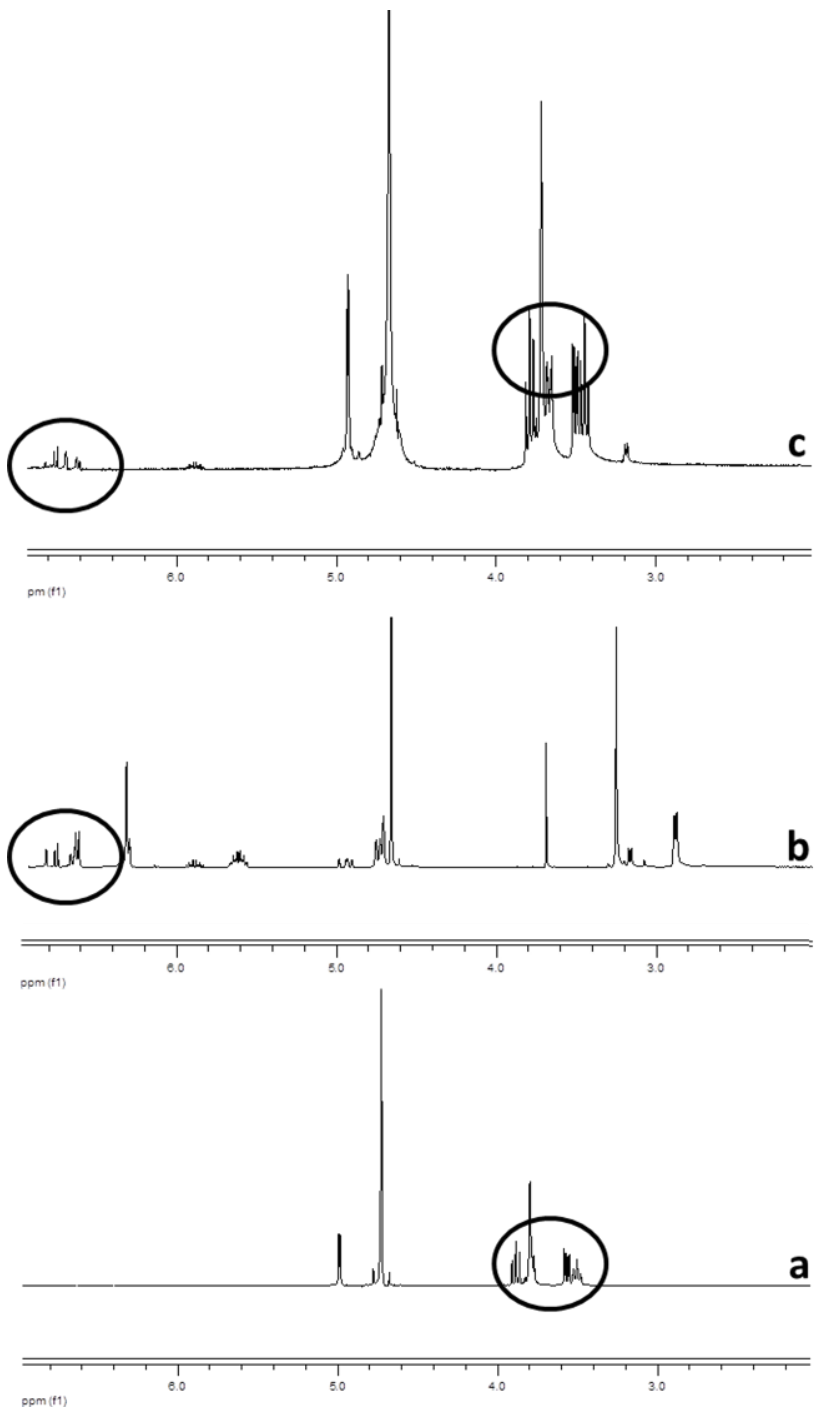
Figure SI-5. Nitrogen adsorption-desorption isotherms for (a) MCM-41, (b) SMPS-Ca,

(c) SMPS-Ci-S, (d) SMPS-Eu and (e) SMPS-Thy mesoporous materials. 
Figure SI-6: $\beta$-CD pure and silica pure after 2, 6 and 15 days inoculated with fungi.

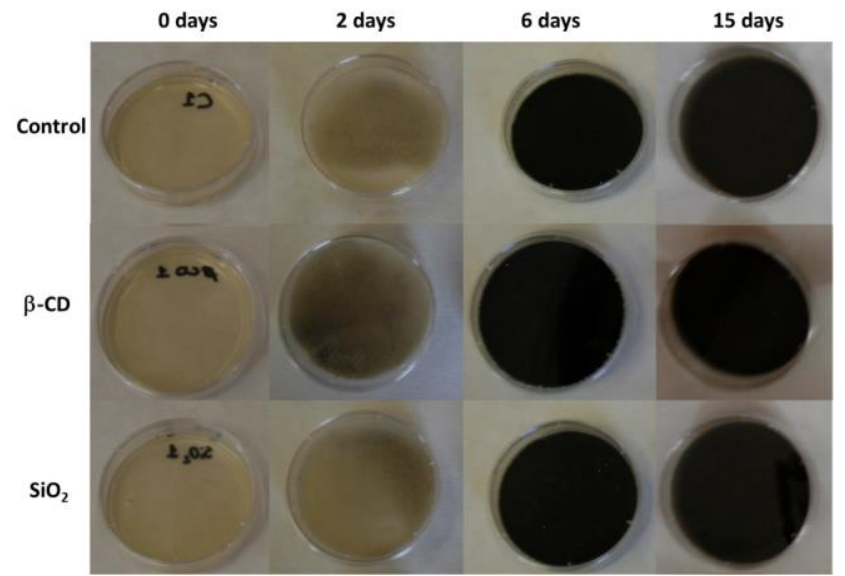

